\title{
The Use of Technology in Portuguese Higher Education: Building Bridges Between Teachers and Students
}

\author{
Anabela Mesquita ${ }^{1,2(\varpi)}$, Paula Peres ${ }^{3}$, and Fernando Moreira ${ }^{4,5}$ \\ ${ }^{1}$ CEOS.PP - ISCAP/IPP, Porto, Portugal \\ sarmento@iscap.ipp.pt \\ 2 Algoritmi RC, Porto, Portugal \\ ${ }^{3}$ ISCAP/IPP, Porto, Portugal \\ pperes@iscap.pt \\ ${ }^{4}$ REMIT, IJP, Univ Portucalense, Porto, Portugal \\ fmoreira@upt.pt \\ 5 IEETA, Univ Aveiro, Aveiro, Portugal
}

\begin{abstract}
The development of technologies together with the new formats, pedagogies and methodologies that they make possible and the characteristics of the youngsters are forcing higher education institutions to change. In order to fill the gap between school and the world outside school, some teachers are adopting and using these technologies. However, there is not enough information available about how they are doing that, if they really use them and, when they do, how do they do it. In this quantitative study, teachers and students were questioned about the use of technologies in the classroom. Results show that although teachers know how to use technology, and advocate they use it, it is still not clear the purpose they use it. The reasons advanced for this situation are the technology itself and, in some cases, with the curriculum. Future work should focus on the analysis of the way teachers really use the technology, thus it will be possible to provide the training and support to help them to fully take advantage of the technologies with pedagogical purposes.
\end{abstract}

Keywords: Higher education · Teachers · Technologies · Youngsters Pedagogy

\section{Introduction}

Higher Education is changing mainly pushed by the use of technologies. This can be visible on the student's profile. According to Prensky [1], today's students have different thinking patterns and process information differently by virtue of their "nativespeaking" ability of the digital language of computers, internet and video games. Moreover, today's digital natives interact (communicate, share, exchange), create, meet, coordinate, evaluate, learn, search, analyze, report, socialize and evolve differently [2], due to a lifetime of exposure to new means of technology. According to the UNESCO [3] students could benefit from the use of technology in education, namely by the 
increased access to information, the flexibility of content and delivery, the combination of work and education, the learner-centered approach, the higher-quality of education and new-ways of interaction. The integration of technologies for innovation and quality in higher education should become a key priority for all institutions. At the higher education level, there should be developed a holistic strategy focusing on the integration of technologies in learning environments, trying to develop networks of knowledge. Teachers should use technology in order to enhance learning, flexibility and efficiency in curriculum delivery. This is a long and a complex process and, according to [4], there are four most common mistakes when introducing technologies into the teaching process, namely: installing learning technology without reviewing student needs and content availability; imposing technological systems from the top down without involving faculty and students; using inappropriate content from other regions of the world without customizing it appropriately; producing low quality content that has poor instructional design and is not adapted to the technology in use. Thus, technological and pedagogical literary is one of the required skills in the current knowledge-based society. Teacher should develop new competences in order to build networks among students, enterprises and knowledge in a digital and global society. In this paper, we try to lead the reflection on if and how teachers are using technologies in the learning environment. In order to meet this goal, we present the background by describing the new generation of students and the impact of the technologies in higher education institutions. Then we present the research design with the aim to bring some light to the discussion about the use teachers make of the technologies in the classroom by comparing and contrasting their perspective with the one from the students. Finally, we draw some conclusions and point out future directions for research.

\section{Background}

\subsection{Generation Z - Who Are They, What Are Their Characteristics?}

Generation Z are called "digital natives" as an attempt to describe their relationship with technology. They are also very engaged with parents, teachers and others. According to [5] members of Generation Z were born between 1995 and 2012, and Crispin Reed coined the term Generation Z in a February 2007 article published in [6]. This generation has a set of traits that was influenced, according to [7] by the Great Recession. The experience has given them a competitive and survivalist mentality, and taught them to be independent, while leading to an entrepreneurial desire. Zers are less likely to resist authority relationships than Gen Yers did, but will only perform for individuals when they are engaged in intensive working relationships. This generation more than any other suffer from the growing gap between the highly skilled and the unskilled. The technical skill gap is huge, but the nontechnical skill gap is even more pervasive. Managing Generation Z requires a huge remedial effort on broad transferable skills like work habits, interpersonal communication, and critical thinking and a huge investment in remedial technical training. Gen Zers prefer a work-life blend, meaning technology puts them always on the clock, and they are masters in the digital world, because they have embraced technology from the crib. 


\subsection{Technology in Education}

The ideal school is the one that meets the students' needs and expectation [8, 19]. However, the ideal school may also mean different things to different authors, leading us to think that we need to rethink learning spaces and curricula. Ryshke [9] states that an ideal school environment is the place where the student's success is a complex goal to achieve, because it is necessary to use many tools to measure and accomplish the teaching-learning process. If teachers are going to meet the needs of all students, they must build a toolbox of strategies that is geared towards diverse learners and learn how to work effectively with each student. The idea brought forward in [9] is discussed and analyzed systematically in [10, 11]. In a study, Lynne Jump [12] states that "whilst there is plenty of evidence that computers and the internet have affected many aspects of daily life, there is also evidence that the use of digital technology is less embedded within university teaching". The use of technologies created wider access to education, new markets for content and expanded revenue opportunities for academic institutions [8, 13]. Online-collaboration tools, software that supports individually paced learning and learning-management systems are among the communications technologies most expected to improve academics over the next five years. Web 2.0 technologies are expected to decline in use over that period. Collectively, such advances may lead to profound changes in the way courses are taught [8]. Inside the classroom, technology may be a disruptive innovation.

\subsection{Barriers to Adopt ICT in Education}

The use of technology in education presents a set of barriers that are often not perceived by teachers when they use or attempt to use them in their classrooms. In [14] two-order barriers are presented: “(i) First-order barriers (...) involve unavailable resources (e.g. lack of equipment, time, or training), and (ii) Second-order barriers (...) involve beliefs about teaching, technologies, established practices, and unwillingness to change". In addition to these external and internal barriers, the author lists barriers grouped into five categories: (i) technology, (ii) process, (iii) faculty, (ix) environment, and (v) administration. Each of these categories is subdivided into subcategories, for example, category (i) includes the following subcategories: Access to technology, Reliability, and Complexity. In a later study [15], this author studies the problem of adoption including two fundamental questions, self-efficacy and the background of teachers, as other barriers in the adoption of new technologies in the teacher and learning process, since changes are necessary, not only in technologies to be adopted, but also in the pedagogy to use them. The proposed solution to overcome these barriers, in particular the last two, is to consider teacher comfort levels regarding technology and pedagogy and to apply Rogers' theories of innovation diffusion [16]. The classic adoption curve indicating a small number of individuals adopting the innovation early, followed by the majority of adopters. So to characterize it we can again use the adoption curve of innovation from Rogers. He classifies people in certain situations during the process of adoption of some new idea, as Innovators, Early adopters, Early Majority, Late Majority and Laggards. To better understand this idea, in [15] an example is presented that addresses the two 
perspectives, technological and pedagogical. The use of an online discussion through a LMS depends on the comfort of the teacher with his/her skills in the use of the LMS; In conclusion, it is necessary to take into account that the use of technology in the TLP, according to [15] "requires a combination of pedagogical and technological comfort."

\section{Research Design}

The purpose of this section is to describe the research design and the procedures used to collect data to answer the following questions: "Are technologies being used in the classroom?"; "Are teachers using them?" and "If not, why?" Since the aim was to compare the perspective of both teachers and students, the research design comprised two stages: (1) with the teachers and (2) with the students. In both stages, we used a quantitative approach, with a survey where data was collected through a structured questionnaire. Data collected for quantitative research through the use of questionnaires requires special care because it is not enough to collect responses about the issues of interest, it is also important to know how to do statistical analysis for proper results validation. Aspects such as the sample size, the way the questionnaire is prepared, the questions formulation, data analysis, error margins, the selection of individual process of who should compose the sample, among other things, are important and they should be taken into account for any investigation [17]. This method is recommended when you want to know a population, to analyze social phenomena and, in cases where it is necessary to inquire a big number of people about a certain subject. In the next paragraphs, we describe the procedures followed in each stage.

\subsection{Stage 1 - Teachers}

As said, a questionnaire was developed. It had 3 groups of questions: (1) Biographical data including gender, age, level of education, year of conclusion, educational institution where the education degree were obtained; (2) Data about the curricular units taught, institution where he/she works, for how many years the person teaches, if the respondents had already had training to use the technologies with students, if the person would like to have such training and if yes, in which area; (3) and finally questions about how the respondent use the technologies in the classroom and why (or why not) he/she uses them. In group 3 we used a 5 point Likert scale ( 1 means "never" while 5 means "always"). In any case, we asked respondents the reasons for their answers. After a validation process, the questionnaire was available online and teachers from both higher education sub systems in Portugal (Universities and Polytechnics) as well as public and private sector, were invited to answer. Data collected were pooled and treated by using the IBM SPSS Statistics 24.0 software.

\subsection{Stage 2 - Students}

The questionnaire for students had 4 groups of questions: a) Group 1 - to characterize the sample such as age, if the person is studying and if yes, what, the format of the course 
in which the respondent is enrolled, if the person has a smartphone and the operation system of this device. This kind of questions helped us to understand if the student was studying and if he/she was familiar with the technologies; Group 2 - the education system (includes questions about social media used, interaction in the social networks, the use of technology in the classroom to interact with colleagues and the social networks used by teachers). In most of these questions we used a 10 point Likert scale where 1 is "not important at all" and 10 is "very important". We also asked the reasons why they think teachers do not use technologies in the classroom, in case they don't. In group 3 we asked questions about the global mind and local reality and comprises questions such as if the persons have already attend a course in a e/b-learning regime, the factors influencing the choice of a course and the preferred teaching methodology. Finally, in group 4 we asked questions to understand the desire to have a diverse community of friends, including colleagues to study as well as the platform used to communicate when this is the case. The questionnaire was also available online. Data collected were pooled and treated by using the IBM SPSS Statistics 24.0 software.

\section{Analysis and Discussion of Results}

In this section, we discuss the results obtained with the questionnaires in both stages teachers and students. However, although there are many results to discuss, by the limited number of pages, only a few are presented and discussed.

\subsection{Stage 1 - Teachers}

The study sample consists of 109 teachers, 54 male and 53 female. The majority of the respondents have between 40 and 60 years old $(70 \%)$, hold a $\mathrm{PhD}(65 \%)$ usually obtained recently (after 2010). Those with a Master or an undergraduate degree are around $14 \%$. $8 \%$ of the respondents have a post-doctorate. $35 \%$ of the respondents work at the Polytechnic of Porto (public institution) while 23\% work at the European University (private institution). The majority of the respondents (more than 60\%) also refers working for more than 15 years and more than $50 \%$ already had training about how to use technologies in the classroom. The majority of the respondents (21 out of 35) say they would like to have some training about how to use technologies in the classroom. Those willing to have this training say this should be in pedagogical use in language teaching and elearning, office package and applications related to financial area. They also would like to use the technology to establish better collaboration and interaction with the students, for the production and edition of media contents and also for IT improvement as the creation of web pages. To sum up, the areas in which teachers want training concern the communication, the collaboration and the production of content. The majority of respondents say they use very often the technologies in the classroom, and those mostly used are the data projector, the laptop and the computer. The tablet and TV are seldom used. As for which applications teachers use with the students and how often, we used the classification advanced in Peres and Pimenta [18] which classifies tools as content production (e.g. Google docs, Prezi, Blogger), communication (synchronous and 
asynchronous) (e.g. Messenger, Skype, Google +, Facebook, Whatsapp, Instagram), share (e.g. YouTube, Slideshare, Onedrive), reference management (Mendely, Zotero, EndNote) and others (e.g. Moodle, Lime survey, b-on). In this situation, the ones that were cited most often in descending order are Moodle (28), Google Docs (24), Dropbox (24), Google Drive (15), Facebook (19), Skype (17), b-on (15), Prezzi (14), End Note (12), One Drive (9), Messenger (9), Power Point (8), WhatsApp (7), Mendeley), Hangou (6), LimeSurvey (5), Slideshare (5) and LinkedIn (4). It is curious to note that the first application to be referred is a Learning Management System (LMS) and the next 3 are mostly used to share files and contents. However, if we compare the results obtained for communication with the ones mentioned above, we can see that when Facebook is referred we might think that it is used not as a communication tool but maybe as a space for a group and sharing contents. The last 2 questions were open and our objective was to understand why or why not teachers used the technologies. The reasons advanced to explain why they do not use (or seldom use) the technologies in the classroom are: "technologies were not applicable to the subjects they taught" or that "they were not necessary" or even that "the applications they used were enough, especially Moodle". Some also responded that it was because "teachers were not trained to use them" or that "they did not know the purpose of the applications". It was also mentioned the fact that "they found the face-to-face contact with the students very important and sometimes this is lost due to the use of the technologies". As for the reasons to use the technologies teachers claimed that it was for the easy creation and storage of files, for the ease and speed in the communication with the students, for allowing the collaborative and participative learning among the students themselves and the teacher and student relationship, making possible an extension to the access to study contents, through the elaboration of more dynamic classes that attract the attention of the students, allowing the implementation of more efficient collaboration and evaluation methodologies, for the possibility of elaboration of materials that can be used later or passed on to other students, among others. According to the results, none of the answers, especially in the open answers, mention the existence of a concern in presenting any guiding reference for the adoption of the tools in the learning activities. That is to say, that the majority of the teachers do not prepare their curricular units taking into consideration or selecting the most adequate tool to develop the competences that they want their students to develop. This observation is reflected in the first four tools mostly used (Moodle, Google Docs, Dropbox, Google Drive), that is, the concern is to maintain the traditional model of teaching and learning. Teachers, mostly use the tools only to make available material in digital format, and for various platforms. Another observation that can be drawn is the set of barriers, which implicitly can be found in the open answers. The top two are self-efficacy and teachers' background. These two barriers are evident when teachers indicate that "the tools were not applicable to the subjects they taught, or that they were not necessary...", underlies the self-efficacy barrier, and "Some also responded that it was because they were not trained to use them or that they did not know the purpose of the applications", underlies the background barrier. Both barriers are explicit here, because the amount of tools available would, in almost all areas, allow them to be adopted. However, this adoption would mean a change in the pedagogical model used, and would require 
training, so it is easier to respond that it is not necessary, or that they do not have adequate training.

\subsection{Stage 2 - Students}

The study sample consists of 337 students that answered the questionnaire. 97,6\% of these were born in the decade of 1990 and the remaining 2,4\% were born in the decade of $1980,96,2 \%$ are still studying. The majority of respondents (84\%) replied they prefer face-to-face learning methods. Only $12,3 \%$ said preferring b-learning method. The remaining respondents didn't reply. The majority $(96,2 \%)$ also said to have a smartphone. Youngsters were also asked which social media they use daily and answers Yes were distributed as: Facebook (280 answers), Instagram (270 answers), Snapchat (210 answers), WhatsApp (150 answers), Twitter (21 answers), Skype (5 answers), YouTube (3 answers), Viber ( 2 answers) and then Pinterest, Outlook and Tinder with one answer each. Youngsters were then asked if their teachers use social media in the learning process. The majority replied "No" (71,8\%). Only 27,5\% said "Yes". Students were also asked to detail which social media teacher used, in case they use: Facebook (110 answers), Twitter (15 answers), Moodle (21 answers), Snapchat (8 answers), LinkedIn (75 answers), WhatsApp (30 answers), Instagram (25 answers) and Skype (21 answers). For the importance of interaction in its different formats, respondents could choose between 1 and 10 where 1 was "not important at all" and 10 was "very important". For the question "How important is social interaction for you?" the answers are concentrated more between 6 and 10 (important and very important). For the question "How important is online interaction for you?" answers are more concentrated between 4 and 8 (important and not so important) while answers for the question "How important is online interaction, when offline, for you?" the answers are even more distributed. This leads us to think that interaction is important for this generation. They value online interaction but when offline, they focus on the offline relations. When asked if they like to interact online with teachers and colleagues, $82 \%$ say "Yes". Respondents were also asked in which situation they use technology. The majority of them (168 out of 231) uses technology to study or do homework. The other possibilities are Leisure (21 answers), Search (13 answers) Information sharing (12 answers), email (10 answers), analysis of documents (4 answers), Social networks (2 answers) and Download programs (1 answer). As for the scientific areas where students use technology, results show they use it in all areas (methodology, law, finances, management, accounting, English, cinema, music, translation, marketing, digital marketing, accounting, photography, medicine, biological science). When comparing results from the question about "if their teachers use social media in the learning process" and question about the situation in which they use technology (above), one can see something at least curious. Respondents say they use very often Moodle to "Study/do homework (Moodle)" with 73\% of the answers while saying that teachers rarely use Moodle. However, if they use Moodle to "Study/do homework (Moodle)" this means that teachers communicate with them via Moodle. This leads us to think that there is some difficulty for teachers to transmit correct message concerning the use of the technology in the teaching-learning process when we are with a generation 
that has and uses technology most of the time (96,2\% has a smartphone). Or that students already see Moodle a commodity and not really as a "technology" teacher uses in classes.

When asked if they would like their teachers to use technology as a support to the learning process, the majority $(96,5 \%)$ say "Yes". As for how could technology be used by teachers to support the learning process, respondents said: In projects (22 answers), to support the study (31), to motivate students (28), to clarify doubts (22), to improve information sharing (21), to provide lessons (5 answers), to motivate students (5), to clarify doubts (12 answers), reduce costs (1), 3D images (1), to evaluate students without pressure (2), to facilitate communication (2), virtual lessons (1), watch videos about the content of lessons (3). Other answers are related with exemplification, innovation, cost reduction, global development, and facilitate looking for a job. The reasons why youngsters think teachers do not use technology were also asked. Students say that "Teachers have the competences but do not have time" and "The content is not adequate for the technologies", with $34 \%$ and $23 \%$ (57\%), respectively. One can conclude that the students have the perception that teachers know how to use the technology but the overall process is not adequate so these "technological" students include it in a formative natural process. To confirm this statement and the previous results, $84 \%$ of the students prefer face 2 face methods and only $12,3 \%$ prefer b-learning.

\section{Comparison Between the Perspective of Teachers and Students}

As seen, teachers state they have the experience in using technologies but they do not fully use them in the learning process. So there is here a gap between what teachers say they know and their actual behavior. The idea of "use" is reinforced when they say they had some training to use the technologies and that they also use them. This leads us to ask ourselves if this knowledge and training teachers say they had, comprised the use of technologies with pedagogical purposes or if it was only the features of the device/ application. And was this training regular or sporadic? How complete was it? Moreover, as teachers say, the technologies they use are the projector, the computer and laptop. Probably their use is mostly to present visual aids such as power points and similar. And as for Moodle, maybe the use of this system is mostly as a repository and not as a true learning platform. The idea of a repository is also expressed by the students when they say they use technology mostly to study and do homework. In fact, Moodle most of the times is used to store documents, files, videos, images, exercises that may help the student to study. The answer to the question - how is technology used in the classroom, apart from the projector and computer? - remains vague. Actually, the answers lead us to think that although technology is everywhere, the only place it is not is in the classroom, apart the use of some devices to project something. And the reasons why teachers do not use are related to the technology itself (not applicable, not necessary) and to the teacher (not trained to or didn't know the purpose). As for students, they say the problem is related with lack of time, the content is not adequate (the same reason advanced by the teacher when he/she says it is not applicable to the subject) and lack of confidence from the teacher. Anyway, these results reveal that technologies are being used in the learning process for some years, the problems of today are the problems of 10 or 15 
years ago - teachers receive training in a certain technology but this training does not cover the aspects related with the pedagogical use of the tool/application. Moreover, this generation of students master the use of technologies. It might be difficult for a teacher in front of a class of 30 or 40 students, to reveal that they do not know everything which might compromise the Aurea of wisdom that the teacher needs to have (or would like to have).

\section{Conclusions}

The discussion of the implementation and use of technologies in education is not new. However, when listening to the arguments presented today and when comparing to those used some years ago, one gets the impression that we have not advanced with any solution since the problem still exists and, probably, has increased in the last years. In fact, on one hand there is this generation that was born in the digital Era, has a smartphone, is perfectly capable to use it and in fact, uses it for different purposes, including studying and being informed and educated (see the formats of e/b/u-learning). On the other side, we have a generation of teachers that were born and raised in a different context, with different tools. They are capable of using these new tools but most of the time they use them for personal purposes, meaning not taking the fully advantage of their potential. The reasons underneath this situation are related with the content of the curriculum, the technology and, of course, the teacher. And this is case, related with the confidence (or lack of it). Results from the survey reveal that teachers are using technology. However, it seems they are using technology to reach only the first level of the Bloom's taxonomy. If they want to achieve a higher level of thinking they need to prepare more complex learning activities supported by technology. As for students, although they are very familiar with the technology, they still prefer face-to-face classes since the interaction and the personal relationships play an important role in their lives. Moreover, students recognized that teachers know how to use technology, but there is a lack of catalytic and inductive models to use technologies in the teaching-learning process allowing this use to become natural while individual and customized. Taking into consideration the results, new questions emerge - how are teachers really using the technologies? Are they using them to promote knowledge, to encourage discussions or are these technologies just to support the share of content? In case this scenario happens to be true, how can we provide some training to revert the situation? What kind of administrative and institutional support should be provided? What kind of incentives should be given to the teachers? The results found in this work are the starting point for further studies in the field of the use technology to support learning process. 


\section{References}

1. Prensky, M.: Digital natives, digital immigrants. Horizon 9(5) (2001). http://www.marc prensky.com/writing/Prensky\%20-\%20Digital\%20Natives,\%20Digital\%20Immigrants\%20\%20Part1.pdf

2. Prensky, M.: The Emerging Online Life of the Digital Native: What they do differently because of technology and how they do it (2004). http://www.bu.edu/ssw/files/pdf/PrenskyThe_Emerging_Online_Life_of_the_Digital_Native-033.pdf

3. UNESCO: Open and Distance Learning Trends, Policy and Strategy Considerations (2002). http://unesdoc.unesco.org/images/0012/001284/128463e.pdf

4. UNESCO: ICTs for Higher Education - Background Paper Commonwealth of Learning, Paris (2009). http://whatis.techtarget.com/definition/ICT4D-Information-and-CommunicationsTechnologies-for-Development

5. LaReau, J.: Work-life balance? for Gen Z, it's work-life blend. Automot. News 91(6) (2017)

6. Reed, C.: What makes 'Y' tick. Brand Strategy 209(38) (2017)

7. Stephen, D.: Move Over Millennials, Here Comes Generation Z: Understanding the 'New Realists' Who Are Building the Future (2015). https://www.prsa.org/Intelligence/Tactics/ Articles/view/11057/1110/Move_Over_Millennials_Here_Comes_Generation_Z_Unde\# VmmUABorKi5

8. Bomsdorf, B.: Adaptation of learning spaces: supporting ubiquitous learning in higher distance education. In: Mobile Computing and Ambient Intelligence: The Challenge of Multimedia. Dagstuhl Seminar Proceedings (2005). http://drops.dagstuhl.de/opus/volltexte/ 2005/371

9. Ryshke, R.: What qualities make for an ideal school or classroom? (2013). https://rryshke. blog/2013/02/24/what-qualities-make-for-an-ideal-school-or-classroom/

10. Bulger, M.: Personalized Learning: The Conversations We're Not Having, Working Paper (2016). https://datasociety.net/pubs/ecl/PersonalizedLearning_primer_2016.pdf

11. Mesquita, A., Moreira, F., Peres, P.: Customized x-learning environment. In: Proceedings of ICERI 2016, 14th-16th November 2016, vol. 1, pp. 835-843 (2016)

12. Jump, L: The experiences of University Lecturers when enhancing their teaching through the use of digital technology: a systematic review, pp. 55-68 (2011). https://www.heacademy. ac.uk/system/files/lynne_jump_greenwich-1.pdf

13. Moreira, F., Ferreira, M.J., Cardoso, A: Higher education disruption through IoT and big data: a conceptual approach. In: Learning and Collaboration Technologies. Novel Learning Ecosystems, Part I. LNCS, vol. 10295, pp. 389-405. Springer (2017)

14. Reid, P.: Categories for barriers to adoption of instructional technologies. Educ. Inf. Technol. 19(2), 383-407 (2014)

15. Reid, P.: Supporting instructors in overcoming self-efficacy and background barriers to adoption. Educ. Inf. Technol. 22(1), 369-382 (2017)

16. Rogers, E.: Diffusion of Innovations. The Free Press, New York (1995)

17. Campenhoudt, L., Quivy, R.: Manual de Investigação em Ciências Sociais. Gradiva Publicações (2008)

18. Peres, P., Pimenta, P.: Teorias e Práticas de b-Learning. Edições Śllabo (2011)

19. Rodrigues, S., Rocha, Á., Abreu, A.: The use of moodle in higher education evolution of teacher's practices over time. In: 2017 12th Iberian Conference on Information Systems and Technologies (CISTI), pp. 1-4. IEEE (2017) 